\title{
(Anti-) coordination in networks
}

Citation for published version (APA):

Kovarik, J., Mengel, F., \& Romero, J. G. (2009). (Anti-) coordination in networks. METEOR, Maastricht University School of Business and Economics. METEOR Research Memorandum No. 041 https://doi.org/10.26481/umamet.2009041

Document status and date:

Published: 01/01/2009

DOI:

10.26481/umamet.2009041

Document Version:

Publisher's PDF, also known as Version of record

\section{Please check the document version of this publication:}

- A submitted manuscript is the version of the article upon submission and before peer-review. There can be important differences between the submitted version and the official published version of record.

People interested in the research are advised to contact the author for the final version of the publication, or visit the DOI to the publisher's website.

- The final author version and the galley proof are versions of the publication after peer review.

- The final published version features the final layout of the paper including the volume, issue and page numbers.

Link to publication

\footnotetext{
General rights rights.

- You may freely distribute the URL identifying the publication in the public portal. please follow below link for the End User Agreement:

www.umlib.nl/taverne-license

Take down policy

If you believe that this document breaches copyright please contact us at:

repository@maastrichtuniversity.nl

providing details and we will investigate your claim.
}

Copyright and moral rights for the publications made accessible in the public portal are retained by the authors and/or other copyright owners and it is a condition of accessing publications that users recognise and abide by the legal requirements associated with these

- Users may download and print one copy of any publication from the public portal for the purpose of private study or research.

- You may not further distribute the material or use it for any profit-making activity or commercial gain

If the publication is distributed under the terms of Article $25 \mathrm{fa}$ of the Dutch Copyright Act, indicated by the "Taverne" license above, 


\section{Maastricht University}

Jaromir Kovarik, Friederike Mengel, José Gabriel Romero

(Anti-) Coordination in Networks

$\mathrm{RM} / 09 / 041$

\section{METEOR}

Maastricht University School of Business and Economics

Maastricht Research School of Economics

of Technology and Organization

P.O. Box 616

NL - 6200 MD Maastricht

The Netherlands 


\title{
(Anti-) Coordination in Networks*
}

\author{
Jaromir Kovarik ${ }^{\dagger}$ \\ University of the Basque Country Maastricht University \\ José Gabriel Romero ${ }^{\S}$ \\ University of Santiago de Chile
}

October 12, 2009

\begin{abstract}
We study (anti-) coordination problems in networks in a laboratory experiment. Participants interact with their neighbours in a fixed network to play a bilateral (anti-) coordination game. Our main treatment variable is the extent to which players are heterogeneous in the number of connections (neighbors) they have. Other network characteristics are held constant across treatments. We find the following results. Heterogeneity in the number of connections dramatically improves the rate of succesful coordination. In addition, even though there is a multiplicity of Nash equilibria theoretically, a very sharp selection is observed empirically: the most connected player can impose her preferred Nash equilibrium almost always and observed Nash equilibria are such that all links are coordinated. As a second treatment variation we let agents decide endogenously on the amount of information they would like to have and find that local (endogenous) information is equally efficient in ensuring succesful coordination as full information. We provide an intuitive explanation of these facts which is supported by our data.
\end{abstract}

JEL-Classification: C72, C90, C91, D85.

Keywords: Game Theory, Networks, Coordination Problems, Experiments.

\footnotetext{
${ }^{*}$ We wish to thank Sanjeev Goyal, Dan Levin, Pedro Rey-Biel, Ingrid Rohde, Jakub Steiner, Martin Strobel and Alexander Vostroknutov as well as seminar participants in Cambridge for valuable comments.

${ }^{\dagger}$ Dpto Fundamentos Análisis Económico I, Universidad del País Vasco/Euskal Herriko Unibersitatea, Av. Lehendakari Aguirre 83, 48015 Bilbao, Spain. jaromir.kovarik@ehu.es

${ }^{\ddagger}$ Corresponding Author. Department of Economics (AE1), Maastricht University, PO Box 616, 6200 MD Maastricht, The Netherlands; Tel:+31-43-38 83891; Fax:+31-43-38 84878; E-mail: f.mengel@maastrichtuniversity.nl

$\S$ Departamento de Economia, USACH, Alameda 3363, Santiago, Chile. gabriel.romero@usach.cl
} 


\section{Introduction}

Coordination in networks is an important problem with implications for development economics (Ray, 2007), technological standard-setting (Katz and Shapiro, 1986), financial regulation (Leitner, 2006) and corruption (Cheloukine and King, 2007) among many others. Understanding how network structure impacts coordination is essential to both: designing networks such that desired outcomes are achieved and being able to target the players in a network with most leverage on coordination process.

Networks in real-life situations are often heterogeneous, i.e. not all agents will have the same number of connections, nor will they be equally "central" in the network. One may wonder whether, and if so how, such heterogeneity might affect coordination. In development economics this question is at the center of an old debate. Hirschman (1958) for example argued that subsidizing "leading" individuals or industry sectors may be crucial for development if these players have leverage and can trigger a transition to a more favorable equilibrium. ${ }^{1}$ Also governments and firms can make use of social networks to increase revenues by targeting certain people in the social network, who have more influence on the outcome of the coordination process. (Galeotti and Goyal, 2009). Moreover understanding how heterogeneity affects coordination in networks is also essential for designing interaction structures within an organization or for industry regulation etc.

An important related question is how much information players need in order to coordinate. If a certain network structure facilitates coordination only if all agents are fully informed about the entire network structure, then this may be problematic. In real life agents will typically only have local information about the network and increasing the amount of information they have may be very costly. In addition it is unclear whether (boundedly rational) agents would actually know how to make use of such additional information.

In this paper we study these problems systematically and ask the following questions: Do heterogeneous networks make it easier for agents to coordinate?, Are more heterogenous networks more likely to induce efficient outcomes?, Who are the "important" players in the network that ensure coordination?, Which players get a bigger share of the "pie" if coordination is successful?, How much information is needed to ensure coordination?

To gain insight into these questions we let participants in an experiment interact in a $4 \times 4$ game which possesses features of coordination and anti-coordination both. Coordination refers to problems where all agents have to take the same action and anti-coordination to situations where agents have to choose different actions in order to reach a Nash equilibrium. Our main treatment variation is the topology of the underlying network. Networks are chosen in such a way that a number of characteristics (number of nodes, links, clustering, characteristic path length, average degree etc.) are held constant, while heterogeneity in degree (the variance in the number of connections) changes. As a second treatment variation we let agents either decide endogenously on the amount of information they would like to see or provide them with full information about the network.

We find the following results

1. Heterogeneity dramatically improves coordination in networks. Coordination is often ensured by the most connected player in the network

2. Even though there is a multiplicity of Nash equilibria theoretically, a very sharp selection is obtained empirically. In particular: (i) coordination is always such that all links are in (bilateral) equilibrium (although theoretically this is not required for Nash equilibrium) and

\footnotetext{
${ }^{1}$ See also Ray (2007).
} 
(ii) the most connected players can impose their preferred Nash equilibrium almost all the time. $^{2}$

3. Local (endogenous) information about the network structure is as efficient as full information in ensuring coordination and yields the same selection of Nash equilibria.

We provide an explanation for these findings using information from our data set. The first result is well explained with a theory of differential adaptation of players with different connectivities, implying that if there is high variance in connections, coordination cycles can be broken or even avoided altogether. The reason is that highly connected agents will adjust actions rarely as a consequence of changes in their neighbour's choices, while their neighbours with few connections will adjust quickly to changes in the highly connected players actions. Hence highly connected players can emerge as leaders in the coordination process. This hypothesis is consistent with the evidence on switching behavior in our data. The second result is best explained by the use of local information together with differential adaptation. In the treatments with endogenous information highly connected players choose the "aggressive" action (leading to their preferred Nash equilibrium) more often if they are informed about higher order neighbors. The reason is that only in this case they realize that they are in a leading position in the network. Consistently with this explanation less connected players choose the aggressive action less often if they know about higher order neighbours. These effects are strongly significant. The third result is quite amazing. It shows on the one hand that very local information is often sufficient to ensure quite succesful coordination, but also that participants are not able to use the additional information in the full information treatment effectively.

Our study is probably the first to show such a strong and significant impact of the network structure on the outcome of a (coordination) game. ${ }^{3}$ Cassar (2007) has studied Coordination in $2 \times 2$ games in local, random and small world networks and has found that the tendency of agents to coordinate to efficient outcomes is slightly higher in small world networks than in others. She also found that both higher clustering coefficients and a shorter characteristic path length have a positive impact on agents choosing payoff dominant actions. In our work we maintain both the clustering coefficient and the average path length constant across our networks and focus solely on the effect of heterogeneity. In Cassar (2007) on the other hand all networks are (a priori) homogeneous. More importantly, though our main research question as well as the underlying game are different. Rather than being interested in the effect of network characteristics on efficiency vs risk dominance we are interested in the effect of the network on coordination per se. In addition we study anti-coordination games rather than coordination games. There is also some relation to work by Choi et al (2009) who study monotone games in networks, where the network mediates only information transmission. They find evidence that the network structure may make some equilibria more salient than others. My et al. (2001) study coordination problems with local vs global interaction and find a slight tendency for local interaction to lead to more coordination on risk-dominant outcomes. ${ }^{4}$

Anti-coordination games on networks have not been studied experimentally to our knowledge. Cooper et al (1993) study the "battle of sexes game" with pairwise random matching and find that coordination failure is very common, occurring in roughly $60 \%$ of the cases.

Theoretical literature on coordination games in networks possibly starts with Blume (1993) and Ellison (1993). ${ }^{5}$ Anti-coordination games in networks have been studied theoretically by Bramoullé

\footnotetext{
${ }^{2}$ We say that a link is in equilibrium if the players connected through the link choose a actions which are mutual best responses.

${ }^{3}$ There is some experimental work by Judd and Kearns (2008) and Charness and Corominas-Bosch (2007) on bargaining games in networks.

${ }^{4}$ See also Corbae and Duffy (2002) or the survey by Kosfeld (2004).

${ }^{5}$ Other papers include Morris (2000) Alos-Ferrer and Weidenholzer (2008), Jackson and Watts (2002), Goyal and
} 
(2007). He analyzes how many agents will choose a certain strategy in a network as it becomes more advantageous and illustrates that the answer to this question differs across networks. ${ }^{6}$ Anticoordination games in evolving networks have been studied theoretically by Bramoullé et al (2004). ${ }^{7}$

The paper is organized as follows. In Section 2 we summarize our research questions. In Section 3 we present the experimental design and in section 4 our main results. Section 5 is dedicated to a discussion of our main results. Some graphs, tables and the experimental instructions can be found in the appendix.

\section{Research Questions}

Our first question is whether and how heterogeneity helps coordination in networks. Let us elaborate on this question a little. In homogeneous networks all players a priori have the same impact on the outcome, whereas in very heterogeneous networks, there are few players who might have a bigger impact on overall play than others since they are linked to more people. Whether they do so depends obviously on the learning (decision) rules agents use. In standard theory with fully rational agents (or more precisely common knowledge of rationality) heterogeneity should not make a difference per se. Also, a priori, the effect might go in either direction. On the one hand highly connected agents may be able to break coordination cycles. ${ }^{8}$ On the other hand "errors" by highly connected players will propagate more easily in the network.

Question 1 (Coordination) Does heterogeneity affect coordination to Nash equilibrium ? Is coordination better in homogenous networks or in heterogenous networks?

A second question that arises is whether in heterogeneous networks agents are more or less likely to coordinate on efficient outcomes rather than risk-dominant ones. If the well connected players exert a higher influence on the network than other players, this question essentially reduces to the question whether they are more likely to choose efficient or risk-dominant actions (and what others believe they will do).

Question 2 (Efficiency) As the network becomes more heterogenous, are agents more or less likely to coordinate on efficient equilibria?

Finally we want to know whether more highly connected agents are aware of their influence on the coordination process and hence are more often able to impose their preferred Nash equilibrium. If these agents realize their importance in the coordination process one may expect such an effect.

Question 3 (Distribution) In heterogenous networks, do agents of higher degree get a bigger share of the pie, i.e. can they impose their preferred Nash equilibrium?

Answering questions 2 and 3 can give us a lot of insight into selection if the network game has multiple Nash equilibria. Knowing which selection will obtain is important information for both the designer of a network as well as for a planner who wants to target central agents in a network, since coordination may not be the only goal of the designer.

An equally important question relates to the amount of information players need to know or to be able to use to ensure coordination. This is our final question.

\footnotetext{
Vega Redondo (2005) and Hojman and Szeidl (2006).

${ }^{6}$ See also Ahmed and Elgazaar (2000). Szabó and Fáth (2007) provide an extensive survey of the literature on evolutionary games on graphs.

${ }^{7}$ Their model has been tested by Berninghaus, Ehrhardt and Ott (2008).

${ }^{8}$ Obviously any agent also in a homogenous network can break a coordination cycles if a sufficient number of people agrees that he/she should do so.
} 
Question 4 (Information) How much information about the network is needed to ensure efficient coordination?

In order to answer these questions we chose the following design of our experiment.

\section{Design}

The experiment was conducted between May and September 2009 at Maastricht University using the software Z-tree (Fischbacher, 2007). 200 students participated in one of the treatments N-1, N-2, N-3, R-1 or R-2. In all treatments participants played the symmetric two player game depicted in Table 1 with their neighbors in the network. ${ }^{9}$

\begin{tabular}{|l|l|l|l|l|}
\hline & $\mathrm{A}$ & $\mathrm{B}$ & $\mathrm{C}$ & $\mathrm{D}$ \\
\hline $\mathrm{A}$ & 20,20 & $\mathbf{4 0 , 7 0}$ & 10,60 & 20,30 \\
\hline $\mathrm{B}$ & $\mathbf{7 0}, \mathbf{4 0}$ & 10,10 & 30,30 & 10,30 \\
\hline $\mathrm{C}$ & 60,10 & 30,30 & 10,10 & $\mathbf{3 0}, \mathbf{4 0}$ \\
\hline $\mathrm{D}$ & 30,20 & 30,10 & $\mathbf{4 0 , 3 0}$ & 20,20 \\
\hline
\end{tabular}

Table 1: The Game.

Each player had to choose the same action against all her neighbors and payoffs in each round are given by the average payoff obtained in all the games against the neighbors. ${ }^{10}$ This is the interesting case to study in networks, since if participants were allowed to choose different actions for their different neighbors, there would essentially be no network effects. The game was repeatedly played for 20 rounds.

Our game is well suited to study our questions, since it involves elements of both coordination and anti-coordination. Equilibria $(\mathrm{A}, \mathrm{B})$ and $(\mathrm{B}, \mathrm{A})$ are efficient while there is a sense in which actions $\mathrm{C}$ and $\mathrm{D}$ risk dominant. (C maximizes payoffs if neighbours choose randomly according to a uniform distribution and $\mathrm{D}$ is the maxmin choice). Hence there is an element of coordination on either efficient or risk-dominant behavior. There is clearly also an element of Anti-Coordination, since within each subset $\{A, B\} \times\{A, B\}$ and $\{C, D\} \times\{C, D\}$ each player has an equilibrium which she strongly prefers and all Nash equilibria are such that the two players have to choose different actions.

The three treatments N-1, N-2 and N-3 differed only in the topology of the underlying network. An equilibrium in a network game (in our experiment of 8 players) is obtained whenever all players choose an action that is a best response to whatever their neighbours choose. All our networks $\mathrm{N}-1$, N-2 and N-3 are such that many pure strategy equilibria exist. Still, it is clear that coordinating a network of 8 players on any one of the many possible equilibria is difficult, especially since players have conflicting interests. We will describe the Nash equilibria in detail at the beginning of Section 3. Both the game and the networks were chosen in such a way that (i) there are many pure strategy Nash equilibria and hence coordination is possible but not obvious, (ii) players have conflicting preferences about these Nash equilibria, (iii) all networks have the same number of Nash equilibria and Nash equilibria are "qualitatively similar" across all networks and (iv) networks are comparable in terms of their characteristics except for the degree of heterogeneity.

The three networks corresponding to our treatments N-1 to N-3 are depicted in Figures 1-3.

The networks were chosen in such a way that starting from the homogeneous network, the circle, heterogeneity in degree is varied while other network characteristics are kept constant. Table 2

\footnotetext{
${ }^{9}$ The game was presented to all participants as if they were row players (see the Instructions in the Appendix).

${ }^{10}$ We chose to pay average payoffs rather than total payoffs to prevent too high inequality in payments among our participants.
} 


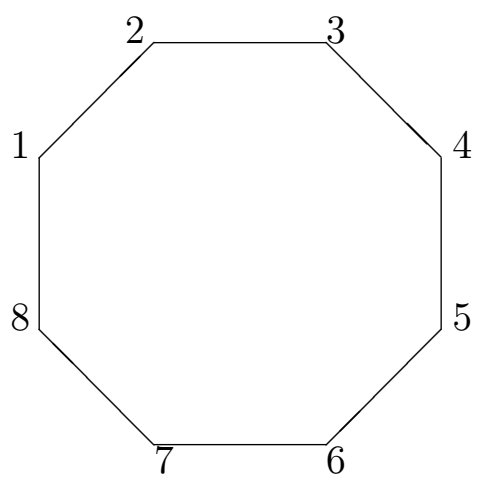

Figure 1: Treatment N-1

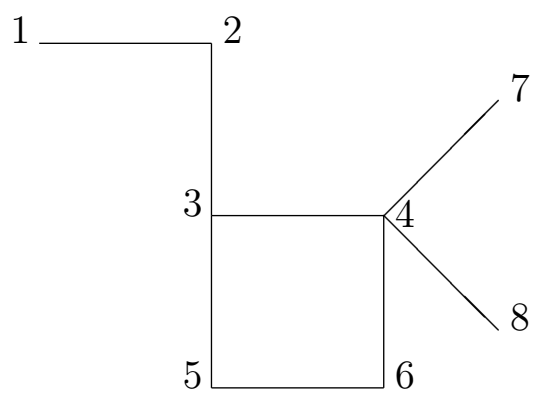

Figure 2: Treatment N-2

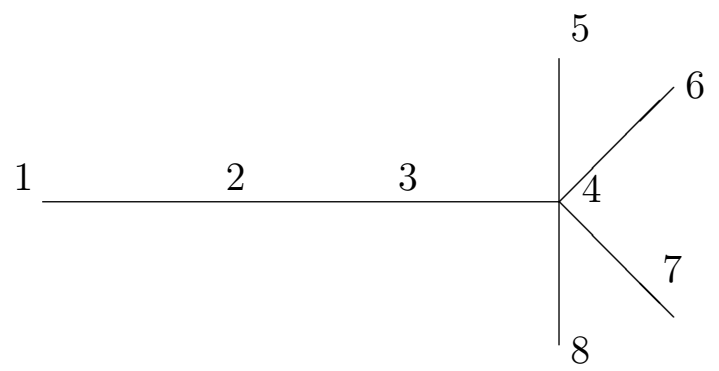

Figure 3: Treatment N-3 
summarizes some characteristics of these networks. $k$ denotes degree and $\sigma^{2}(k)$ the variance in degree. The characteristic path length of a network is the average length of the shortest path between any two agents and the betweenness of an agent/node measures the share of shortest paths that pass through her. The average betweenness is the average of the betweenness measures across all nodes. Betweenness is often used to measure the centrality of a node in the network. We consider two measures of heterogeneity in degree. One obvious candidate is certainly the variance in degree $\sigma^{2}(k)=\sum_{i=1}^{8}\left(k_{i}-\bar{k}\right)^{2}$. This measure of heterogeneity, though, neglects the network structure to a certain extent in that it does not account for correlation between neighbour's degrees. For example it may be possible that variance is very high in one part of a network but very low in another part of the network. Hence as a second measure we use the minimal variance across all (non-trivial) partitions of the network. Consider partitions $G$ of $N$ s.t. (i) each $g \subseteq G$ is connected and (ii) $\operatorname{card}(g) \geq 3, \forall g \in$ $G .{ }^{11}$ Then we can define this second measure as $\sigma_{\min }^{2}=\min _{G}\left(\min _{g \in G} \sum_{i \in g}\left(k_{i}-\bar{k}\right)^{2}\right)$.

\begin{tabular}{|l|l|l|l|}
\hline & $\mathrm{N}-1$ & $\mathrm{~N}-2$ & $\mathrm{~N}-3$ \\
\hline number of players & 8 & 8 & 8 \\
\hline number of links & 8 & 8 & 7 \\
\hline average degree $\bar{k}$ & 2 & 2 & 1.75 \\
\hline$\sigma^{2}(k)$ & $\mathbf{0}$ & $\mathbf{8}$ & $\mathbf{1 6 . 5}$ \\
\hline$\sigma_{\text {min }}^{2}$ & $\mathbf{0}$ & $\mathbf{2}$ & $\mathbf{0 . 6 8}$ \\
\hline charact. path length & 2.14 & 2.21 & 2.21 \\
\hline clustering coeff. & 0 & 0 & 0 \\
\hline average betweenness & 0.42 & 0.40 & 0.37 \\
\hline variance betweenness & 0 & 0.21 & 0.21 \\
\hline
\end{tabular}

Table 2: Network Characteristics.

As can be seen from Table 2, all the networks are very similar in terms of most network characteristics, with the exception of our heterogeneity measures, the variance in degree $\sigma^{2}(k)$ and the minimal variance across non-trivial partitions $\sigma_{\min }^{2}$. Network N-3 is much more heterogenous than network N-2 which is in turn much more homogenous than $\mathrm{N}-1$ according to $\sigma^{2}(k)$ but in terms of $\sigma_{\min }^{2} \mathrm{~N}-2$ is more heterogenous than $\mathrm{N}-3$ (than $\mathrm{N}-1$ ). Naturally the heterogeneity in degree also induces some heterogeneity in betweenness and there are slight difference in the average betweenness across networks as well in the variance in betweenness (where the difference is mostly between N-1 and the other networks). Hence another question we can ask is whether it is mostly the difference in degrees or in betweenness which will drive our results. Overall these networks are well suited to study our research questions described above.

To be able to interpret our results more easily we wanted to control for the amount of information participants use. Hence in treatments $\mathrm{N}-1$ to N-3 we did not simply provide them with all the information about the network, their neighbors actions and payoffs but we asked them at the end of each round which information they would like to obtain. They could choose to have information about the identity, actions and/or payoffs of their first-order, second-order, third-order and/or fourthorder neighbors. Each piece of information had a small cost of 1 ECU (experimental currency unit). Requesting information about the network had a cost of $10 \mathrm{ECU}$, since this information is permanent and was also permanently displayed to the participants once they had requested it. In treatments R-1 and R-2 there was no information request stage and all the information was displayed all the time to all participants. Other than that R-1 coincides with N-1 and R-2 with N-2.

\footnotetext{
${ }^{11}$ If a subset of players is not connected, then the variance within this subset is meaningless. The second condition ensures that there are at least three players in a subset, since variance for two players is trivial.
} 
Controling for the amount of information participants have about the network has two advantages. First it helps us to understand and interpret our data much better. And second it addresses our last research question about the amount of information needed to coordinate.

Finally, the fact that we also wanted to investigate information search was one motovation to use networks of 8 players. In smaller, more stylized, networks most participants have only first-order neighbours and hence it is not possible to investigate information search in a meaningful way. The larger the network, though, the harder it is to achieve coordination for the participants and the noisier our data will become.

The experiment lasted between 60-90 minutes and participants earned between 7,70 and 16,30 Euros with an average of 11,40 Euro.

\section{Results}

Before we start to describe our experimental results, we would like to describe the set of Nash equilibria in the three networks more formally.

Claim (Nash equilibria) Irrespective of the network $N-1, N-2$ or $N$-3

(i) there are four pure strategy $N E$-profiles where all links are in $N E,{ }^{12}$

(ii) there are no additional pure strategy equilibria where all players choose the "efficient" actions, $A$ or $B$ and

(iii) there are eight more pure equilibria where some players choose $C$ and some D.

Proof. Appendix.

The claim shows that all of our networks have the same number and structure of Nash equilibria. Hence standard theory does not lead to different predictions for these networks. Note also that coordination cycles are equally possible in all networks if agents learn e.g. via myopic best responses. On the other hand the claim shows that there is a large multiplicity of equilibria, which means that theory makes only weak predictions about the outcome of the network games. ${ }^{13}$ The actual behavior we observe in the experiment, though, eliminates this multiplicity. As we will see below, out of the 12 theoretically possible Nash equilibria we only observe one or two empirically. We will now proceed to present our experimental results and we will give an explanation for them in Section 5.

\subsection{Coordination}

Let us start with the first research question concerning coordination. Since it is easily possible in a network of eight players that one or two players make mistakes, we consider three measures for coordination to NE in order to account for this possibility. Our measures are the percentage of cases (across the last 5 rounds) in which the entire network is in Nash equilibrium (NE) and the percentage of cases (also across the last 5 rounds) in which the entire network would be in Nash equilibrium if one (two) players changed their action, denoted by NE-1 (NE-2). The results are presented in Tables $3 \mathrm{a}$ and $3 \mathrm{~b}$.

\footnotetext{
${ }^{12}$ All equilibria are explicitly described in the Appendix.

${ }^{13}$ Standard refinements do not remove this multiplicity. Also if assume e.g. that agents learn via myopic best responses and then consider stochastic stability, the multiplicity of stochastically stable states remains.
} 


\begin{tabular}{|l|l|l|l|l|l|l|l|}
\hline & N-1 & N-2 & N-3 \\
\hline NE & 0.12 & 0.32 & 0.24 \\
\hline NE-1 & 0.28 & 0.71 & 0.40 \\
\hline NE-2 & 0.36 & 0.89 & 0.72 \\
\cline { 2 - 5 }
\end{tabular}, \begin{tabular}{llll} 
NE & 0.13 & 0.46 \\
\hline NE-1 & 0.13 & 0.67 \\
\hline NE-2 & 0.40 & 0.87 \\
\hline
\end{tabular}

Tables 3(a,b): Percentage of successful coordination in last 5 rounds.

The table illustrates that coordination is much better in heterogenous networks than in the homogeneous network $\mathrm{N}-1$. In fact the rate of successful coordination is twice as high in N-3 than in $\mathrm{N}-1$ and almost three times higher in N-2 compared to N-1. All treatment differences are pairwise highly significant across N-1, N-2 and N-3 (Mann-Whitney, $p<0.0001$ ). The difference between NE-1 in N-1 and R-1 is marginally significant $(p=0.0864)$. Other differences between N-1 and R-1 or differences between N-2 and R-2 are not statistically significant. (Mann-Whitney, $p>0.2865$ $(p>0.3413))$.

Result 1 Coordination to Nash equilibrium is significantly better in the heterogenous network N-2 than in $N-3$ and significantly better in $N-3$ than in $N-1$.

If we look at the measures NE-1 and NE-2 coordination in the heterogeneous networks (especially $\mathrm{N}-2$ ) is impressive with around $80 \%$ of networks coordinated in the last 5 rounds. Note also that deviations of a single player from NE need not always represent errors. In one network N-2 we observed for example that starting from the NE where player 4 chooses D (and all links are in NE), player 4 sometimes started to switch to B for some rounds, possibly to induce a transition to the efficient NE. No other player reacted though for three rounds and player 4 switched back to D.

A first conclusion from this data is that our more "local" measure of the variance $\sigma_{\min }^{2}$ describes the relevant heterogeneity better than the simple variance $\sigma^{2}(k)$. We will present a more detailed explanation of Result 1 in Section 5.1. Figures 4-6 show the percentage of coordination over time. The figures illustrate clearly the difference in coordination rates across the three networks. ${ }^{14}$ The figures also show that the coordination failure in N-1 seems persistent, i.e. not simply a matter of the speed of convergence. Of course it cannot be ruled out that convergence would occur after "enough" periods in $\mathrm{N}-1$, but from an empirical point of view this difference is semantic. Convergence which occurs only after a very large period of time is (i) not interesting for policy and (ii) not empirically distinguishable from non-convergence if the time needed for convergence is longer than the duration

\footnotetext{
${ }^{14}$ The graphs for R-1 and R-2 look similar (to N-1 and N-2) and are available upon request. Convergence can also be studied by comparing the switching rates across the treatments. The concave shape of the cumulative distribution functions in Figure 9 for N-2 and Figures A-1 and A-2 for N-1 and N-3 illustrate that switching rates decline over time.
} 
of institutions.

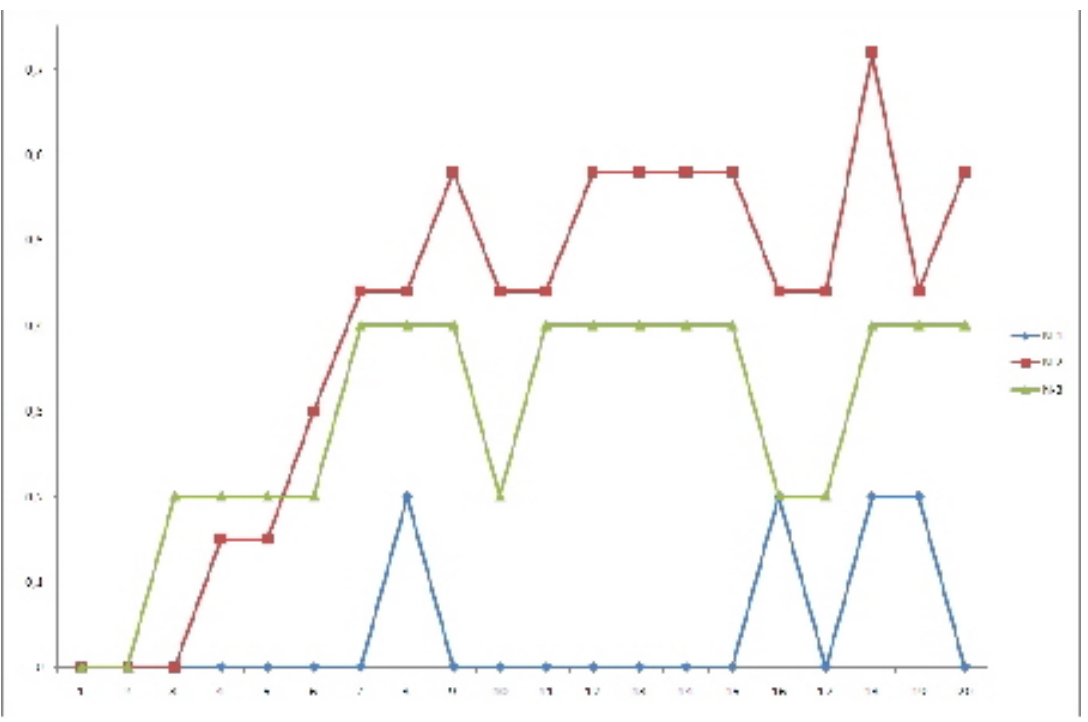

Figure 4: Coordination to Nash equilibrium (NE) over time $(\mathrm{N}-1$ to $\mathrm{N}-3)$.

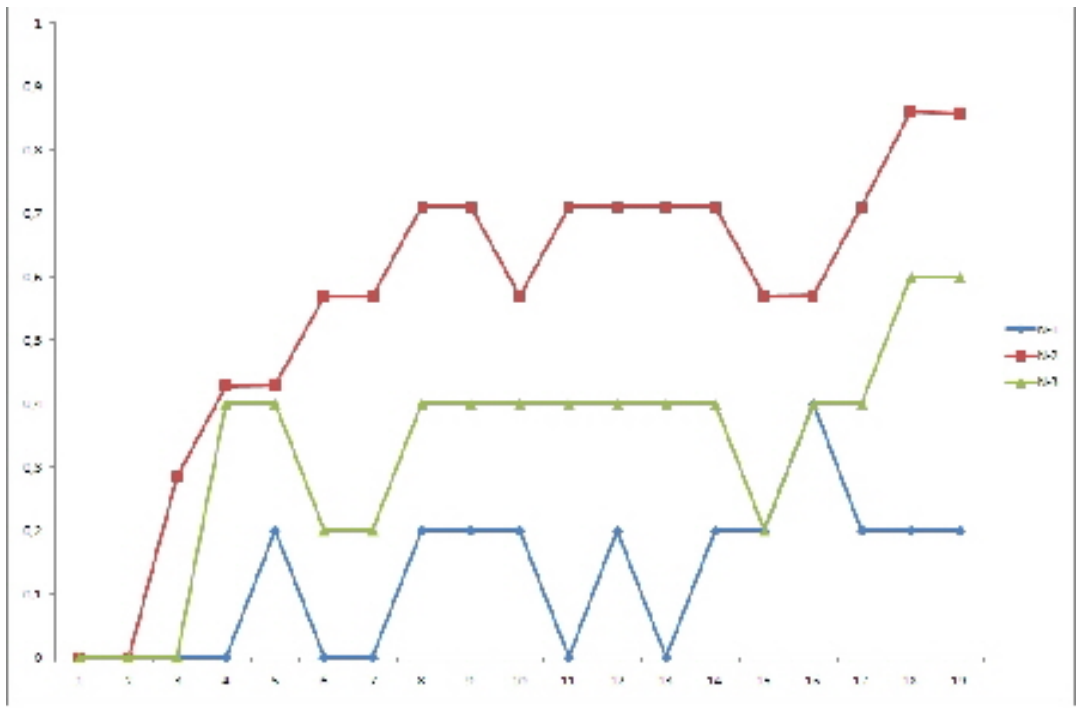

Figure 5: Coordination to Nash equilibrium (NE-1) over time (N-1 to N-3). 


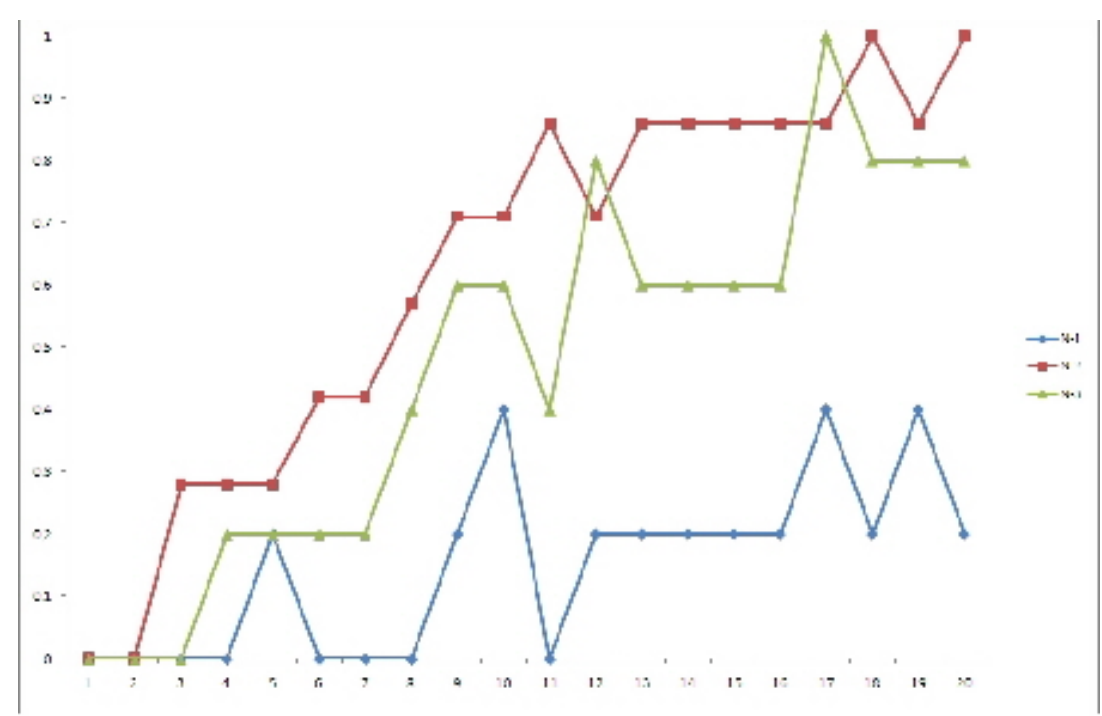

Figure 6: Coordination to Nash equilibrium (NE-2) over time (N-1 to N-3).

As mentioned above the fact that a network is in Nash equilibrium does not imply that a Nash equilibrium of the two player game needs to be played along all links. ${ }^{15}$ We consider as a second measure the percentage of links in Nash equilibrium across the last five rounds of play and find a qualitatively similar pattern.

\begin{tabular}{|l|l|l|l|}
\hline & $\mathrm{N}-1$ & $\mathrm{~N}-2$ & $\mathrm{~N}-3$ \\
\hline \% of links in NE & 0.55 & 0.74 & 0.72 \\
\hline
\end{tabular}

The treatment differences between $\mathrm{N}-1$ and the other treatments are pairwise highly significant (Mann-Whitney, $p=0.0056(\mathrm{~N}-1$ vs N-2) and $p=0.0038(\mathrm{~N}-1$ vs N-3)). The difference between $\mathrm{N}-2$ and N-3 is not. Interestingly, thus, we find that given this measure coordination is not worse in N-3 than in $\mathrm{N}-2$. We will give an explanation of this fact below.

Note also that - given that players choose uniform randomly either of two actions - the probability for a link to be coordinated on a NE is $50 \%$. A binomial test rejects the hypothesis that $50 \%$ of links are coordinated in the last 5 rounds for $\mathrm{N}-2$ and N-3 $(p<0.000001)$ but not for the homogenous network N-1 ( $p=0.137367)$. Hence coordination in the homogenous network is not much better than if all players did choose randomly among two actions. (As we will see in the following subsection $90 \%$ of choices in $\mathrm{N}-1$ are only either $\mathrm{C}$ or $\mathrm{D})$.

\subsection{Efficiency}

Table 4 lists action choices across the last 10 periods of the experiment for the different treatments. The risk-dominant actions $C$ and $D$ are chosen in $90 \%(91 \%, 83 \%)$ of all rounds in treatments $\mathrm{N}-1$, $\mathrm{N}-2$ and N-3. The differing percentages of $C$ and $D$ choices in the homogeneous network $\mathrm{N}-1$ reflect the extent of coordination failure illustrated in the previous subsection. In treatment $\mathrm{N}-3$ the efficient actions $\mathrm{A}$ and $\mathrm{B}$ were chosen more often than in $\mathrm{N}-1$ and N-2. A Mann-Whitney test rejects the hypothesis that the distribution of efficient vs non efficient choices are equal in N-3 and N-1 (N-2) $(p=0.0330, p=0.0043)$. There are no significant differences between N-1 and N-2 (Mann-Whitney, $p=0.5964)$.

\footnotetext{
${ }^{15}$ Table A-3 in the Appendix shows some Nash equilibria where this is not the case
} 


\begin{tabular}{|c|c|c|c|c|c|c|}
\hline & $\mathrm{N}-1$ & N-2 & $\mathrm{N}-3$ & & $\mathrm{R}-1$ & R-2 \\
\hline $\mathrm{A}$ & 0.04 & 0.04 & 0.09 & $\overline{\mathrm{A}}$ & 0.05 & 0.00 \\
\hline $\bar{B}$ & 0.06 & 0.05 & 0.08 & $\bar{B}$ & 0.13 & 0.03 \\
\hline $\mathrm{C}$ & 0.37 & 0.45 & 0.35 & $\mathrm{C}$ & 0.33 & 0.46 \\
\hline $\mathrm{D}$ & 0.53 & 0.46 & 0.48 & $\mathrm{D}$ & 0.49 & 0.51 \\
\hline $\mathrm{C}+\mathrm{D}$ & 0.90 & 0.91 & 0.83 & $\mathrm{C}+\mathrm{D}$ & 0.82 & 0.97 \\
\hline
\end{tabular}

Table 4: Distribution of Choices last 10 Periods

Efficient actions were also chosen more often in R-1 rather than in N-1. This treatment difference is significant (Mann-Whitney, $p=0.0004$ ), but there is no significant difference between N-2 and R-2 (Mann-Whitney, $p=0.1700$ ). The fact that there is no difference between N2 and R-2, while there is a difference between $\mathrm{N}-1$ and R-1 is likely due to faster convergence in treatments $\mathrm{N}-2$ and R-2. in fact if we look at choices in the first 5 periods of the game we do find significant differences also for those treatments with $23 \%$ of choices being A or B in treatment N-2 versus $31 \%$ in treatment R-2.

Result 2 In all treatments $N-1, N-2$ and $N-3$ agents mostly try to coordinate on risk-dominant outcomes, but choose "efficient actions" $A$ and B significantly more often in $N-3$ than in $N-1$ or $N$-2 and more often in $R$-1 compared to $N$-1.

\subsection{Which Nash equilibria?}

Despite Result 2 we also observe that if coordination occurs it is always on a Nash equilibrium where all players choose risk-dominant actions. Such a conclusion though depends largely on the payoff matrix chosen and is hence to be enjoyed with care. Still we can make even stronger statements regarding selection.

As mentioned above theoretically not all links need to be in Nash equilibrium in order to have a Nash equilibrium of the network game. Theoretically there is quite some ambiguity. Empirically, though, we observe strong regularities. In fact among those profiles which were a NE in the last 5 rounds $100 \%$ where NE where all links are coordinated in all networks N-1, N-2, N-3 and R-2. For the measure NE-1 the percentage is $100 \%(100 \%, 80 \%, 100 \%)$ for $\mathrm{N}-1(\mathrm{~N}-2, \mathrm{~N}-3$ and $\mathrm{R}-2)$ and for NE-2 it is $100 \%(100 \%, 84 \%, 100 \%)$. In R-1 we have only very few instances of convergence. In this treatment $0 \%$ of NE (NE-1) were such that all links are coordinated and $67 \%$ of NE-2 were such that all links are coordinated.

Result 3 In all treatments $N$-1, $N$-2, $N$-3 and $R$-2, if there is convergence to Nash equilibrium, then participants coordinate always on a Nash equilibrium where all links are coordinated.

This is quite an amazing result which suggests that coordination to such equilibria is easier. We will give an explanation for this fact in Section 5. We have narrowed down the multiplicity of equilibrium outcomes that arises theoretically to only two Nash equilibria arising empirically. In fact, as the following subsection shows, we can make even more precise predictions in heterogeneous networks. ${ }^{16}$

\footnotetext{
${ }^{16}$ This has the caveat that efficient equilibria may arise for different payoff matrices. This caveat does not apply to Result 3, since changing the payoffs for any particular action does not affect how the different classes of equilibria are ranked in terms of individual payoffs (as long as no equilibria appear or disappear).
} 


\subsection{Distribution}

In this subsection we aim to answer our third research question, i.e. we would like to know whether more connected agents can impose their "preferred" Nash equilibrium more often than others. To these ends we have a closer look to which Nash equilibrium players coordinated in the heterogenous networks. Conditional on being coordinated on a Nash equilibrium at all (or being coordinated except for one or two players) we then have the following share of coordination on player 4's preferred Nash equilibrium.

\begin{tabular}{|c|c|c|c|c|}
\hline & $\mathrm{N}-2$ & N-3 & & R-2 \\
\hline $\mathrm{NE}$ & 0.82 & 0.71 & $\mathrm{NE}$ & 1.00 \\
\hline NE-1 & 0.78 & 0.80 & NE-1 & 1.00 \\
\hline NE-2 & 0.78 & 0.90 & NE-2 & 0.93 \\
\hline
\end{tabular}

Table 5: NE preferred by player with highest degree

The difference between N-2 and R-2 is significant at the $10 \%$ level (Mann-Whitney, $p=0.0725$ ) for NE, but all other pairwise treatment differences are not significant. This result is pretty amazing, since it shows that the most connected players can impose their preferred Nash equilibrium most of the time and in the case of full information even all the time. Together with the previous results this allows us to make sharp predictions about the outcome of the game in spite of the large multiplicity of Nash equilibria. This is most striking in the case of full information (R-2) where one particular Nash equilibrium out of 12 possible equilibria is always observed. In N-2 and N-3 two Nash equilibria are observed. In both risk dominant actions are chosen and all links are coordinated and in more than $80 \%$ of the time the NE which player 4 prefers is observed.

Result 4 In the heterogenous networks $N$-2, $N$-3 and $R$-2 players coordinate (almost) all the time on a Nash equilibrium preferred by the most connected player.

We will provide an explanation of this fact in Section 5. Note first, though, that this selection of Nash equilibria is also reflected in the payoffs. The following table summarizes the average payoffs of participants in $\mathrm{N}-2$ conditional on their position in the network $1, . .8$.

\begin{tabular}{|l|l|l|l|l|l|l|l|l|}
\hline N-2 & 1 & 2 & 3 & 4 & 5 & 6 & 7 & 8 \\
\hline Payoffs & 647 & $\mathbf{7 3 4}$ & 673 & 694 & $\mathbf{7 3 9}$ & 637 & 622 & 585 \\
\hline (Std. Dev.) & $(54)$ & $(62)$ & $(51)$ & $(66)$ & $(77)$ & $(74)$ & $(70)$ & $(64)$ \\
\hline \hline R-2 & & & & & & & & \\
\hline Payoffs & 690 & $\mathbf{8 1 0}$ & 677 & $\mathbf{7 7 4}$ & 720 & 696 & 703 & 643 \\
\hline (Std. Dev.) & $(34)$ & $(80)$ & $(22)$ & $(12)$ & $(70)$ & $(47)$ & $(47)$ & $(27)$ \\
\hline
\end{tabular}

In network N-2, players 2 and 5 make the highest payoffs. The distribution of payoffs differs significantly from that of player 1 (Mann-Whitney, $p=0.0356, p=0.0381$ ), player $3(p=0.0011, p=$ $0.0011)$, player $7(p=0.0105, p=0.0113)$ and player $8(p<0.0001, p=0.0001)$, but not from that of players $4(p=0.2692, p=0.2789)$ and $6(p=0.4906, p=0.4892)$. The reason that players 2 and 5 make higher payoffs is of course that their preferred Nash equilibrium is played more often. In addition - unlike player 4 - they do not have the burden to "ensure" cooperation, as we will see in Section 5 ..

In R-2, where coordination is even better, players 2 and 4 make the highest payoffs. The distribution of payoffs for these players is significantly different from that of all others $(p<0.0001)$ with the exception of the comparison between player 4 and 5. Again the reason is that their preferred $\mathrm{NE}$ is played all the time, but unlike in $\mathrm{N}-2$ player 4 now does not suffer so much from having many neighbours since convergence is extremely quick in R-2. 


\begin{tabular}{|l|l|l|l|l|l|l|l|l|}
\hline N-3 & 1 & 2 & 3 & 4 & 5 & 6 & 7 & 8 \\
\hline Payoffs & 662 & $\mathbf{6 9 4}$ & 650 & $\mathbf{6 9 4}$ & 629 & 626 & 658 & 626 \\
(Std. Dev.) & $(170)$ & $(46)$ & $(72)$ & $(64)$ & $(62)$ & $(55)$ & $(119)$ & $(49)$ \\
\hline
\end{tabular}

In N-3 it is Players 2 and 4 that make the highest profits, but pairwise payoff differences in this treatment are not significant probably due to worse convergence. (Mann-Whitney, $p>0.1167$ ).

Result 5 Players 2 and 5 make significantly higher payoffs than all others in network $N$-2 and players 2 and 4 in $R$-2.

\subsection{Information}

To conclude this section let us have a look at what information agents asked for in treatments N-1 to N-3. Since there were no significant differences in information search across those treatments we report aggregate data in the following graphs. ${ }^{17}$ Figure 7 shows the percentage of participants per round that requested info about their first- (second-, third-, fourth-) order neighbours conditional on having a first- (second-, third-, fourth-) order neighbour. Figure 8 shows the percentage of participants per round that request information about their first- (second-, third-, fourth-) order neighbours 'actions again conditional on having a first- (second-, third-, fourth-) order neighbour.

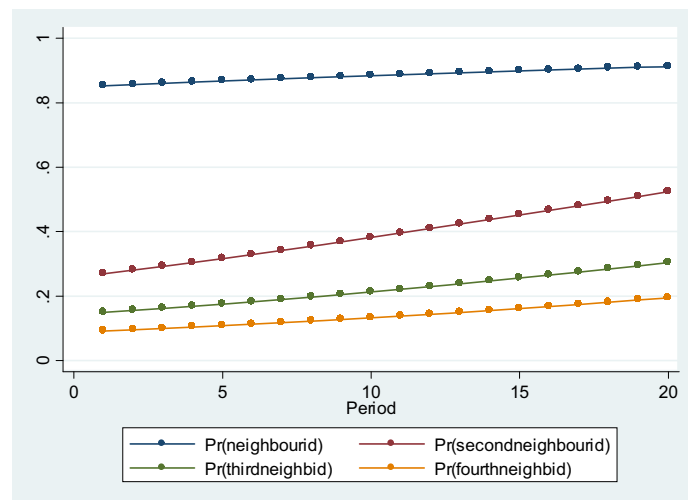

Fig. 7: Information about Neighbours

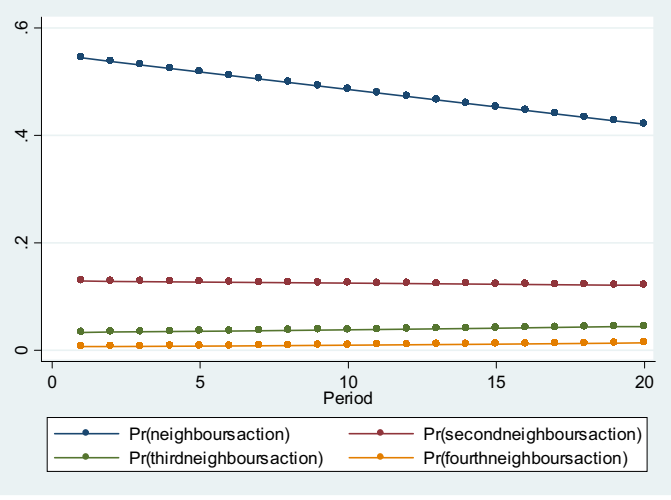

Fig. 8: Information about Actions.

The vast majority of agents $(>90 \%)$ request information about who their first-order neighbours are and most also want to know what their first-order neighbours chose in at least half of the rounds. Out of those that do not check their neighbours actions still quite some check their own payoff and less than $10 \%$ of agents do not request any information at all. Around $45 \%$ of agents request information about their second-order neighbours in addition. There is a slightly decreasing trend in the frequency with which participants check their neighbor's action choices, which is consistent with the fact that there is much less variation in choices over the last ten period compared to the first ten periods and hence less can be learned from this information.

Overall we can see that participants in the N-treatments rely mostly on local information about their first or second order neighbours. The fact that very much the same behavior is observed in the R-treatments as in the N-treatments provides strong evidence that participants are not able to use higher order information effectively. On the other hand we see that very local information (about mostly first and sometimes second order neighbours) is sufficient to guarantee succesful coordination.

\footnotetext{
${ }^{17}$ Separate graphs per treatment are available upon request.
} 
Result 6 Local (endogenous) information is as efficient as full information in ensuring successful coordination.

The fact that we are able to observe which information participants used, enables us to say something more about the underlying reasons for our results. We will now proceed by studying the data in more depth to explain the results we described above. We will start with our result on Coordination.

\section{Explanation and Discussion}

\subsection{Coordination}

Our conjecture is that heterogeneity might help coordination, since it induces differing adjustment rates between highly connected players and less connected players. In order to gain more insight into whether this is the case, we look at the adjustment rates across different players in our networks.

The following table shows the switching rates of players in network N-2. The first observation is that - non-surprisingly - there are many more switches in cases where the network did not coordinate on a Nash equilibrium. It can also be seen that players 4 and 6 switch actions less often than other players and player 1 much more. Note that in particular the cases where coordination is successful are characterized by player 4 switching much less than other players. Player 1 who is at the largest distance of player 4 switches actions much more often than others. In general players seem to switch actions less often if they are closer to player 4 or if they have more neighbors.

\begin{tabular}{|l|l|l|l|l|l|l|l|l|}
\hline $\mathbf{N - 2}$ & 1 & 2 & 3 & $\mathbf{4}$ & 5 & 6 & 7 & 8 \\
\hline NE & 8 & 7.2 & 6 & $\mathbf{4 . 4}$ & 6 & 5.1 & 7.3 & 6.4 \\
\hline no NE & 13.5 & 11.5 & 9 & $\mathbf{9}$ & 9 & 8.5 & 6.5 & 10.5 \\
\hline overall & 9.6 & 7.6 & 7 & $\mathbf{6}$ & 7.1 & 6 & 7.1 & 7.4 \\
\hline
\end{tabular}

Table 6: Switching rates per network position in N-2.

This renders support to the theory that it is the agents with the higher degree which are able to break coordination cycles, since they have more neighbors and hence react less strongly to changes in one of their neighbor's actions. If the variance in degree is high than in addition the neighbors of the highly connected agents will have a smaller degree and hence are more likely to adapt their action to the highly connected agents choice. This differential reaction to each others choices is what avoids or breaks coordination cycles.

In addition, if players do understand this effect, then it can be exploited by the most connected players to impose their preferred Nash equilibria. We will see in subsection 5.2 that some of this seems to take place.

The following graph shows the cumulative distribution of action switches in network $\mathrm{N}-2$. The curves are normalized to player 1's higher switching rates. What can be seen quite clearly from the graph is that a) curves appear to be concave and b) the curve for player 4 (graphed thicker and black) slows down earlier than that of other players. Hence, as could be expected, switches decrease over time indicating convergence and secondly player four seems to "lead" convergence since her 
switching rate declines earlier than those of other players on average.

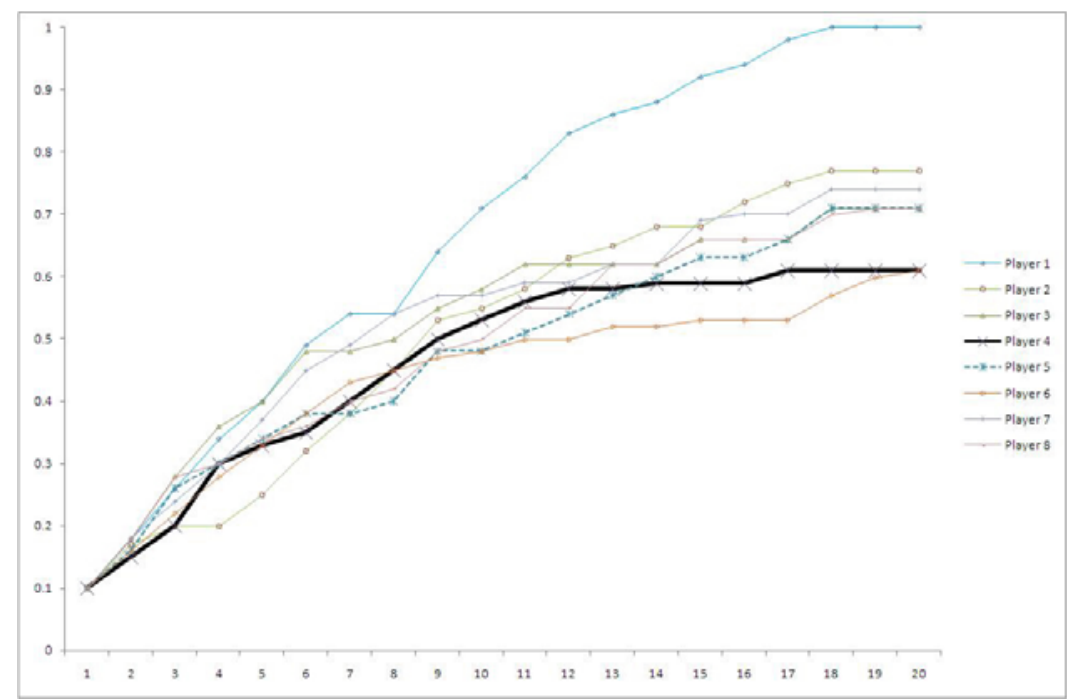

Figure 9: Cumulative Distribution of Switches in N-2.

Why is coordination worse, though, in N-3 the network with the higher variance than N-2, but with a smaller minimal variance across partitions of the graph ? If our explanation is correct, then coordination should be much worse in the part of the network which has a smaller variance. Hence we look in the following table at the percentage of time in the last 5 rounds in which the "homogeneous" subset $\{1,2,3\}$ and the "heterogeneous subset" $\{4,5,6,7,8\}$ are in Nash equilibrium. Note that since the first set is smaller we should expect a higher percentage of coordination there. In addition if we want to use the measure NE-1, the analysis becomes trivial in a line of three players. Hence we also report coordination in the subset $\{1,2,3,4\}$.

\begin{tabular}{|l|l|l|l|}
\hline N-3 & NE & NE-1 & NE-2 \\
\hline$\{1,2,3\}$ & 0.24 & - & - \\
\hline$\{1,2,3,4\}$ & 0.24 & 0.44 & - \\
\hline$\{4,5,6,7,8\}$ & 0.40 & 0.76 & 0.92 \\
\hline
\end{tabular}

Table 7: Coordination in subgraphs N-3

Table 7 impressively illustrates the origin of the coordination failure in network N-3. While in the subnetwork $\{4,5,6,7,8\}$ the rates of successful coordination are as high (or even higher) as in $\mathrm{N}-2$, coordination is much worse in the subnetwork $\{1,2,3\}$, even though it consists of 3 players only. The table also illustrates that the subnetwork $\{1,2,3\}$ is almost entirely responsible for the coordination failure in network N-3 and fully responsible for the difference between N-3 and N-2. This renders strong support to our conjecture. This effect is possibly reinforced by the fact that agents use local information only and hence players 1 and 2 are not aware of the fact that player 3 is connected to the most connected player 4.

Note that this observation also explains why the percentage of links coordinated is not lower in N-3 compared to N-2. Since the subgraph $\{4,5,6,7,8\}$ is almost always coordinated, the number of non-coordinated links is very small in N-3. In particular those cases which are not counted as Nash equilibria even for the measure NE-2 often correspond to cases where most links are coordinated in the subgraph $\{4,5,6,7,8\}$. 
Finally inspection of Figure A-2 in the Appendix illustrates that while players 4-8 clearly switch actions less often over time, no such trend can be made out for players 1-3 in treatment N-3. This confirms the results from Table 7 .

Summary Successful coordination is driven by the most connected player switching actions less often, while her less connected neighbours adapt quickly to her choices. The most connected player emerges as a "leader" in coordination. Since agents use local information only coordination is most effective if the minimal variance across connected subnetworks is high.

\section{Why are (almost always) all links coordinated in NE ?}

The fact that successful coordination requires some leaders and that players using local information tend to adjust always to their neighbor which displays more stable behavior can also explain why in the Nash equilibria which are empirically observed almost always all links are in NE. Successful Coordination is characterized by fewer switches on average with some players emerging as leaders and others adjusting to their behavior. As an example consider the only network N-1 in which coordination was successful. Switching behavior in this network is depicted in Figure 10. The average number of switches was only 4.8 in this network and it can be clearly seen from the graph that some leaders emerged who never switched actions starting from round 3. In this network the leader was player 3 who was choosing action D.

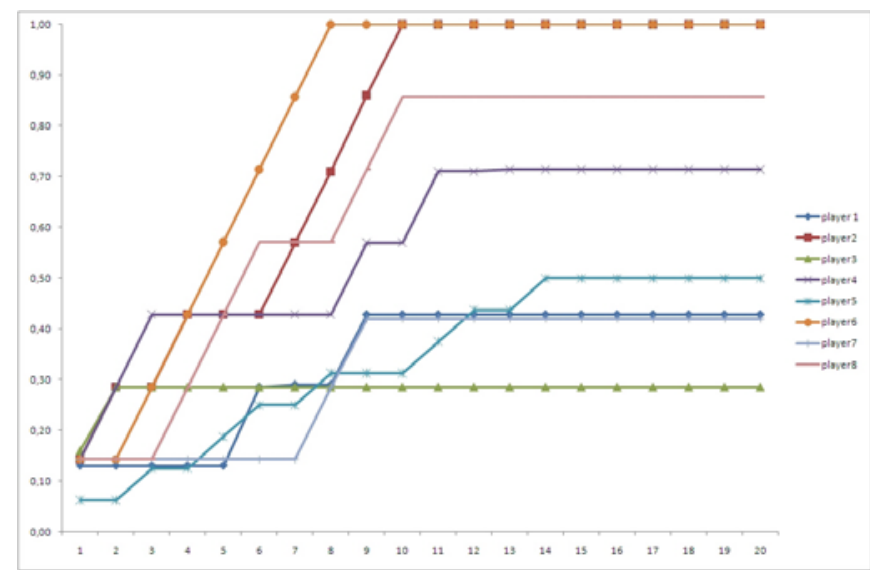

Figure 10: Succesful Coordination in N-1.

Hence two conclusions emerge: 1) successful coordination requires the presence of "leaders" who switch actions less often and 2) this implies that there is a tendency in NE for all links to be coordinated.

\subsection{Information Search and "Hawk" Choices}

A second observation we made is that the most connected agents are almost always able to impose their preferred Nash equilibrium (See results 4 and 5). In this subsection we will evaluate two candidate explanations. The first is that action $\mathrm{D}$ is simply perceived as the better response for a more connected player, since it might be consistent with player 4 facing more or less risk than other players. The second is that the most connected players realize their importance in the coordination process and hence impose their preferred Nash equilibrium. 
It is the second explanation which is strongly supported by our data. The minimization of risk hypothesis seems not to work well. Let's have a look at the difference (in percentage points) between action choices among players 4 and other players in the early periods 1-10.

\begin{tabular}{|l|l|l|l|}
\hline "Player4-others" & $\mathbf{N - 2}$ & $\mathbf{N - 3}$ & $\mathbf{R - 2}$ \\
\hline A & -0.02 & -0.05 & 0.00 \\
\hline B & $\mathbf{0 . 1 3}$ & $\mathbf{0 . 3 0}$ & $\mathbf{0 . 1 6}$ \\
\hline C & -0.13 & -0.09 & -0.20 \\
\hline D & 0.02 & -0.16 & 0.04 \\
\hline
\end{tabular}

Table 8: Difference in Choice between Player 4 and others in early periods (1-10)

In early periods players 4 do not choose $D$ much more often than others, but they choose $B$ much more often than other players. Clearly choosing $B$ is not consistent with an hypothesis that players 4 face more risk, since $C$ obviously dominates $B$ in terms of risk. One may sustain hence that players 4 actually face less risk than other players and hence are more willing to choose risky actions. If this were the case, then it should also be true (to some extent) for player 3 in networks N-2 and R-2 at least in early periods, since they have more neighbours than other players (except for player 4). We compare hence action choices of player 3 in N-2 and R-2 to those of other neighbours of player 4 .

\begin{tabular}{|l|l|l|}
\hline "Player3-other Neighb." & $\mathbf{N - 2}$ & $\mathbf{R - 2}$ \\
\hline A & -0.04 & 0.00 \\
\hline B & -0.04 & -0.03 \\
\hline C & $\mathbf{0 . 2 3}$ & $\mathbf{0 . 1 1}$ \\
\hline D & -0.15 & -0.08 \\
\hline
\end{tabular}

Table 9: Difference in Choice between Player 3 and other neighbours of player 4 in periods 1-10

It can be seen that player 3 , having more neighbours, does choose $C$ more often in early periods than other neighbours of player 4 what is consistent with the fact that $C$ is perceived as risk-dominant. (See our analysis of questionnaire data in subsection 5.6).

On the other hand, if the second explanation is right, than it seems that highly connected agents should play D with higher probability if they do have information about second (or higher) - order neighbors and hence realize that they have a higher degree than others. Without such information $\mathrm{C}$ seems to be the more likely choice (especially in early periods) since it is risk-dominant and hence one may expect coordination to an equilibrium where the most connected player chooses $\mathrm{C}$. We conducted a Spearman test to find out the correlation between the "hawkish" B- and D-choices and information search (about second neighbors). The results are presented in the following table

\begin{tabular}{|l|l|l|}
\hline Player & $\mathbf{N - 2}$ & $\mathbf{N - 3}$ \\
\hline $\mathbf{4}$ & $\boldsymbol{\rho}=\mathbf{0 . 2 4 7 0}^{* * *}$ & $\boldsymbol{\rho}=\mathbf{0 . 1 7 0 1}^{*}$ \\
\hline 3 & $\rho=0.0428$ & $\rho=-0.0153$ \\
\hline 5 & - & $\rho=-0.2200^{* *}$ \\
\hline 6 & $\rho=-0.4145^{* * *}$ & $\rho=-0.0116$ \\
\hline 7 & $\rho=-0.0749^{* *}$ & $\rho=-0.4203^{* * *}$ \\
\hline 8 & $\rho=-0.2256^{* * *}$ & $\rho=-0.1670^{*}$ \\
\hline
\end{tabular}

Table 10: Correlation betw. "Hawk Choices" and Information Search by network position.

Table 10 clearly illustrates that those player 4 who are informed about second-order neighbours and hence about the fact that they have a relatively higher degree than others choose D significantly 
more often than those who are not. On the other hand player 4's immediate neighbours (with the exception of Player 3) choose D significantly less often if they are informed about second-order neighbours and hence about their relatively lower degree compared to player 4 . For player 3 we do not find a significant effect which is probably due to the fact that player 3 herself has a relatively high degree in $\mathrm{N}-2$.

This result also means that agents are very well aware of the leading role highly connected agents play in the coordination process. The highly connected players seem to use this knowledge to impose their preferred Nash equilibrium while their neighbours are willing to "give in" more easily if they are aware of the special role of player 4 . We also checked whether the amount of coordination itself in the last 10 periods is correlated to whether agents have information about their second order neighbours and find no significant effects, which is consistent with the explanation given above. This also means that the correlations identified above are not simply a by-product of better coordination in these cases.

Summary If the most connected players are aware of their importance for the coordination process they tend to choose "hawkish" actions B and D significantly more often. They are able to impose their preferred Nash equilibria because of their leading role in the coordination process. Differences in risk cannot explain this phenomenon.

\subsection{Information Search and Efficiency}

In this section we try to explain some of our observed treatment differences in efficiency. Let us start with the difference we observe between $\mathrm{N}-3$ and treatments $\mathrm{N}-1$ and N-2. The first observation is that $53 \%$ of the efficient choices are made by players $\{5,6,7,8\}$ another $30 \%$ by players 3 and 4 and only $17 \%$ by players 1 and 2 . Hence players 3 and 4 choose efficient actions almost twice as often as players 1 and 2 .

We can also correlate the choice of efficient actions with information and we find no such correlations in $\mathrm{N}-1$ and $\mathrm{N}-2(p>0.1447)$, whereas in treatment $\mathrm{N}-3$ we do find that those players that ask for information about higher-order neighbors choose efficient actions more often $(\rho=0.1406$, $p=0.0004$ ). If we look at the same correlates by player, we find that those players 4 who are better informed about higher order neighbors choose efficient actions less often while other players choose the efficient action more often.

\begin{tabular}{|l|l|l|l|l|}
\hline $\mathbf{N - 3}$ & 1 & 2 & 3 & 4 \\
\hline & $0.2448^{* *}$ & $0.6875^{* * *}$ & $0.1898^{*}$ & $\mathbf{- 0 . 2 2 2 4} 4^{* *}$ \\
\hline & 5 & 6 & 7 & 8 \\
\hline & $0.1729^{*}$ & $0.3025^{* *}$ & $0.2371^{* *}$ & $0.2199^{* *}$ \\
\hline
\end{tabular}

Table 11: Correlation between Efficient Choice and Information Search in N-3.

Jointly this evidence suggests that the most connected player 4 tries to implement the efficient equilibrium sometimes, but the better she is informed about far away neighbours (such as player 1 and 2) the more often she chooses risk-dominant actions. Coordination to the efficient action hence seems to fail in the homogeneous subnetwork $\{1,2,3\}$. On the other hand the better informed the peripheral players are the more likely they are to choose an efficient action, because in this case they observe (i) the central players 3 and 4 choosing efficient actions more often and (ii) they realize that player 4 has many neighbours and is hence (as our evidence demonstrates) more important for the coordination process. 
Similarly we find that agents in the homogeneous network R-1 choose efficient actions somewhat more often than in $\mathrm{N}-1$, possibly, because of better information. In homogeneous networks more information may enhance the willingness of players to choose efficient actions since less risk is perceived by players. In fact there is a theoretical result by Alos-Ferrer and Weidenholzer (2008) showing that a larger information radius makes it more likely that efficient actions emerge in Coordination games if players rely on a certain form of imitation learning. Our experimental analysis gives partial support to this conclusion but suggests that it may depend strongly on the social network itself.

For network N-2 we can do the same type of analysis and find less clear-cut and only marginally significant results, which are likely due to the fact that fast convergence occurred in this network.

\begin{tabular}{|l|l|l|l|l|}
\hline N-2 & 1 & 2 & 3 & 4 \\
\hline & $-0.0961^{*}$ & 0.0000 & $-0.1698^{* *}$ & $-0.1419^{*}$ \\
\hline & 5 & 6 & 7 & 8 \\
\hline & $-0.3358^{* *}$ & 0.1400 & $0.1399^{*}$ & -0.00259 \\
\hline
\end{tabular}

Table 12: Correlation between Efficient Choice and Information Search in N-2.

Overall it seems that (i) heterogeneity may help coordination to efficient actions and that (ii) more information enhances efficient play if networks are homogeneous but not if networks are very heterogenous. More research is needed, though.

\subsection{Which network characteristics matter more ?}

It is quite clear that if players use local information of the network only they are simply not aware whether they or their neighbors have higher betweenness while (at least if they pay attention to second order neighbors) they are well aware who has the higher degree. Of course this does not imply that betweenness need not matter for coordination. It does imply, though, that coordination can be improved if agents realize the fact that players with higher degree will switch less often, while no such reasoning is possible regarding betweenness.

Let us investigate this question a bit further We ran a binary logit regression for a players choice of either an "aggressive" or "Hawk" action $(B$ or $D)$ vs "Dove" actions $(A$ or $C) .{ }^{18}$ We regressed on the following variables: a player's degree $k$, her maximal distance from other players and her betweenness. ${ }^{19}$ Note that all these characteristics are highly correlated. Hence we decided to regress a players choice of "hawkish" action on any combination of those three and then ranked the regressions according to (i) the Akaike information criterion and (ii) the share of variance explained $\rho$. We restrict attention to the first two digits of $\rho$ and no digits for the Akaike criterion and then compare regressions bilaterally according to these measures. We say a regression is better than another regression if it is weakly better according to both criteria. This produces the following table of "best" regressions.

\footnotetext{
${ }^{18}$ We also ran multinomial logit regressions taking into account all options $A, B, C$ and $D$. The regressions yield similar results and are available upon request. In particular we find that a higher degree implies more D choices (significant at 1\%-level), less A and less C-choices (significant at 1\%-level) and more B-choices (not significant).

${ }^{19}$ Those measures can be found in the Appendix.
} 


\begin{tabular}{lllll} 
"Hawk" & $(\mathrm{N}-2)$ & $(\mathrm{N}-3)$ & $(\mathrm{R}-2)-\mathrm{a}$ & $(\mathrm{R}-2)-\mathrm{b}$ \\
\hline const. & -0.38225 & 0.03964 & $-1.27245^{* *}$ & $4.88964^{* * *}$ \\
& $(0.48810)$ & $(0.41233)$ & $(0.80352)$ & $(1.6983)$ \\
$k$ & $0.34399^{*}$ & 0.18315 & $0.97704^{* * *}$ & \\
& $(0.12189)$ & $(0.08923)$ & $(0.36101)$ & \\
distance & & & & $-1.38311^{* * *}$
\end{tabular}

$(0.49339)$

betweenness

\begin{tabular}{lllll}
\hline \hline Akaike & 1262 & 920 & 512 & 512 \\
$\rho$ & 0.4290 & 0.3879 & 0.4439 & 0.4373 \\
\hline
\end{tabular}

Table 13: panel data logistic Regression, prob. to choose $B$ or $D$, $\left(\left(\operatorname{Pr}>\varkappa^{2}\right)<0.0001\right) ;{ }^{* * *} 1 \%,{ }^{* *} 5 \%,{ }^{*} 10 \%$.

Due to the high correlation among explanatory variables the "best" regressions involve one explanatory variable only. In N-2 and N-3 a unique regression is better than all others, which is regressing only on a player's degree. In R-2 regressing on a player's degree and on the maximal distance produces the same performance according to both measures.

This leads us to conclude that consistently with the use of local information only degree seems to matter most in determining whether a player chooses "hawkish" actions.

\subsection{Robustness}

The robustness treatments R-1 and R-2 have shown that our results are robust to the amount of information participants have. This is likely due to the fact that even if participants have full information they effectively take into account only the information they would request anyhow. ${ }^{20} \mathrm{In}$ addition in many real-life settings partial information is the relevant case.

As a final robustness check, though, we analyzed whether those agents that did not check any information (in most of the rounds, i.e. more than 10 times) received lower or higher average payoffs than those that did. This can be an indicator of whether it was worthwhile to look for information. Non-surprisingly we find that in N-2 this is not the case (two sided Mann-Whitney, $p=0.5378$ ), since in this network convergence is very good. ${ }^{21}$ If we focus uniquely on the first five rounds of play (before convergence occurred) there is a negative effect of not searching information, though, which is significant at the $5 \%$ level. In N-1 on the other hand, where convergence to NE is very bad, we find that those agents which check information very rarely make substantially smaller profits (with an average of 27) than those which check information regularly, which average 34.7. (Mann-Whitney, $p=0.0018$ ). In N-3 we find a similar effect. Not searching information yields significantly lower payoffs especially across the first ten rounds (Mann-Whitney, $p=0.0006$ ). Overall hence we find that information search was worthwhile for participants but that local information proved enough to ensure successful coordination.

\footnotetext{
${ }^{20}$ For more on this see Kovarik, Mengel and Romero (2009).

${ }^{21}$ Also we find no significant differences in information search among players with different network positions, suggesting that the amount of search is largely non-strategic.
} 


\subsection{Questionnaire Data}

In this last subsection let's have a look at our questionnaire data, where we elicited risk attitudes. Those date can serve as a check of whether are treatments were balanced in terms of risk attitudes and whether we interpret the riskiness of actions in the same way participants do. We asked participants three questions regarding their risk attitudes in a post-experimental questionnaire:

1. We toss a coin in the air. Choose one of the following options: (i) Receive $1000 €$, independently of the outcome of the toss coin. (ii) Receive $2000 €$ if head turns up or $0 €$ if tail turns up.

2. Choose between the two following options the one you prefer: (i) Play a lottery ticket, in which you win $45 €$ with probability $80 \%$, or $0 €$ with probability $20 \%$. (ii) Receive $30 €$.

3. We toss a fair coin. Do you accept the following deal: If head turns up you get $150 €$, while if tail turns up you loose $100 €$. Yes/No

Not a single one of our participants chose the coin toss in question 1, 48.5\% of our participants preferred the lottery in question 2 and $28.5 \%$ accepted the coin toss in question 3 . We then categorize our participants into three categories: the most risk averse participants, which chose the safe outcome each time $(r=0)$, those that accepted one of the three lotteries $(r=1)$ and those that accepted two lotteries $(r=2)$. The distribution across treatments of these types was as follows

\begin{tabular}{|l|l|l|l|l|l|}
\hline & $\mathrm{N}-1$ & $\mathrm{~N}-2$ & $\mathrm{~N}-3$ & $\mathrm{R}-1$ & $\mathrm{R}-2$ \\
\hline$r=0$ & 0.45 & 0.53 & 0.45 & 0.46 & 0.41 \\
\hline$r=1$ & 0.38 & 0.31 & 0.38 & 0.30 & 0.38 \\
\hline$r=2$ & 0.17 & 0.16 & 0.17 & 0.24 & 0.22 \\
\hline
\end{tabular}

We find no significant differences in the pairwise comparison between treatments in the proportion of "least risk averse" $(r=2)$ participants (Mann-Whitney, $p>0.2816)$ or "most risk averse" $(r=0)$ participants (Mann-Whitney, $p>0.1217$ ) with the exception of the comparison between $\mathrm{N}-2$ and R-1 for $r=0$ (Mann-Whitney, $p=0.0462$ ).

Next we check whether participants classified as "most risk averse" $(r=0)$ choose the efficient (but more risky) actions $A$ and $B$ more or less often. The results can be found in the following table.

\begin{tabular}{|l|l|l|l|l|l|}
\hline $\mathrm{N}-1$ & $\mathrm{~N}-2$ & $\mathrm{~N}-3$ & $\mathrm{R}-1$ & $\mathrm{R}-2$ & overall \\
\hline-0.0170 & 0.0004 & $-0.0841^{* *}$ & $-0.1401^{* *}$ & -0.0461 & $-\mathbf{0 . 0 4 8 5 ^ { * * * }}$ \\
\hline
\end{tabular}

Clearly the results show that risk-averse participants choose the risky actions significantly less often overall. If we separate data per treatment, the effect is only significant in N-3 and R-1, which is where efficient actions where played more often. We also check whether those players 4 who are classified as "risk-loving" choose the risk-dominant action $C$ more or less often and again we find strong and strongly significant results.

\begin{tabular}{|l|l|l|l|}
\hline Player 4 & $\mathrm{~N}-2$ & $\mathrm{~N}-3$ & $\mathrm{R}-2$ \\
\hline$r=2$ vs $C$ & - & $-0.2004^{* *}$ & $-0.3350^{* * *}$ \\
\hline$r=0$ vs $C$ & 0.1212 & - & $0.3050^{* * *}$ \\
\hline
\end{tabular}

Since actions $C$ and $D$ are chosen with much higher probability in all treatments the effect appears much stronger here compared to the table above. Players 4 classified as "risk-loving" choose action $C$ much less often. This illustrates that $C$ is perceived as risk-dominant which is consistent with our analysis in subsection 5.2. (In treatment $\mathrm{N}-2$ all players 4 where classified as $r=1$ or $r=0$ ). The 
opposite result is also true. Players 4 classified as very risk-averse $(r=0)$. choose $C$ much more often than others. (Again in N-3 no player 4 was in this category).

Overall the results from the questionnaire show that we can be confident in the quality of our data as well as in the fact that our definition of risky actions coincided with that of the participants.

\section{References}

[1] Ahmed, E. and A.S. Elgazaar (2000), On coordination and continuous hawk dove games in small world networks, Eur. Phys. J. B 18, 159-162.

[2] Alos-Ferrer, C. and S. Weidenholzer (2008), Contagion and Effiency, Journal of Economic Theory 143(1), 251-274.

[3] Berninghaus, S., K. Ehrhardt and M.Ott (2008), Myopically Forward Looking Agents in a Network Formation Game, working paper SFB 504.

[4] Blume, L. (1993), The Statistical Mechanics of Strategic Interaction, Games and Economic Behavior 5(3), 387-424.

[5] Bramoullé, Y. (2007), Anti-Coordination in Networks, Games and Economic Behavior 58, 30-49.

[6] Bramoullé, Y., S. Goyal, D. Lopez-Pintado and F. Vega-Redondo (2004), Network Formation and Anti-Coordination Games, International Journal of Game Theory 33, 1-19.

[7] Cassar, A., (2007), Coordination and cooperation in local, random and small world networks: Experimental Evidence, Games and Economic Behavior 58(2), 209-231.

[8] Charness, G. and M. Corominas-Bosch (2007), Bargaining and network structure: An Experiment, Journal of Economic Theory 136(1), 28-65.

[9] Cheloukine, S. and J. King (2007), Corruption networks as a sphere of investment activities in modern Russia, Communist and post-communist studies 40(1), 107-122.

[10] Choi, S., D.Gale, S. Kariv and T.Palfrey (2009), Network Architecture, Salience and Coordination, working paper UCL.

[11] Cooper, R., D.V. DeJong, R. Forsythe and T.W. Ross (1993), Forward induction in the battleof-the-sexes games. American Economic Review 83, pp. 1303-1316.

[12] Corbae, D. and J. Duffy (2002), Experiments with Network Economies, mimeo University of Pittsburgh.

[13] Ellison, G. (1993), Learning, Local Interaction and Coordination, Econometrica 61(5), 10471071.

[14] Fischbacher, U. (2007), z-Tree: Zurich toolbox for ready-made economic experiments. Experimental Economics 10 (2): 171-178.

[15] Galeotti, A. and S. Goyal (2009), Influencing the Influencers: A theory of strategic diffusion, RAND Journal of Economics 40(3), 509-532.

[16] Goyal, S. and F. Vega-Redondo (2005), Network formation and social coordination, Games and Economic Behavior 50, 178-207. 
[17] Hirschman, A. (1958), The Strategy of Economic Development, New Haven, CT: Yale University Press.

[18] Hojman, D. and A. Szeidl (2006), Endogenous Networks, Social Games and Evolution, Games and Economic Behavior 55 (1), 112-130.

[19] Jackson, M. O. and A. Watts (2002), On the formation of interaction networks in social coordination games, Games and Economic Behavior 41, 265-291.

[20] Judd, S. and M. Kearns (2008), Behavioral experiments on networked trade, Proceedings of the 9th ACM conference on Electronic commerce.

[21] Katz, M.L. and C. Shapiro (1986), Technology Adoption in the Presence of Network Externalities, Journal of Political Economy 94(4), 822-842.

[22] Kosfeld, M. (2004), Economic Networks in the Laboratory: A survey, Review of Network Economics 3: 20-41.

[23] Kovarik, J., F. Mengel and J.G. Romero (2009), Learning in Networks, mimeo Maastricht University.

[24] Leitner, Y. (2006), Financial Networks: Contagion, Commitment and Private Sector Bailouts, The Journal of Finance 60:6, 2925-2953.

[25] Morris, S. (2000), Contagion, Review of Economic Studies 67, 57-78.

[26] My, K.B., M. Willinger and A. Ziegelmeyer (2001), Global versus Local Interaction in Coordination Games: An Experimental Investigation, BETA-working paper.

[27] Ray, D. (2007), Development Economics, New Palgrave Dictionary of Economics eds L.Blume and S.Durlauf.

[28] Szabó, G. and G. Fath (2007), Evolutionary Games on Graphs, Physics Reports 446, 97-216.

\section{A Appendix}

\section{A.1 Network Characteristics}

\begin{tabular}{|l|l|l|l|l|l|l|l|l|}
\hline betweenness & 1 & 2 & 3 & 4 & 5 & 6 & 7 & 8 \\
\hline $\mathrm{N}-2$ & $\frac{14}{56}$ & $\frac{26}{56}$ & $\frac{36}{56}$ & $\frac{38}{56}$ & $\frac{21}{56}$ & $\frac{21}{56}$ & $\frac{14}{56}$ & $\frac{14}{56}$ \\
\hline $\mathrm{N}-3$ & $\frac{14}{56}$ & $\frac{26}{56}$ & $\frac{34}{56}$ & $\frac{38}{56}$ & $\frac{14}{56}$ & $\frac{14}{56}$ & $\frac{14}{56}$ & $\frac{14}{56}$ \\
\hline
\end{tabular}

Tables A-1 and A-2: Characteristics of network positions. 


\section{A.2 Nash equilibria}

\begin{tabular}{|c|c|c|c|}
\hline $\mathrm{NE}$ & $\mathrm{N}-1$ & $\mathrm{~N}-2$ & $\mathrm{~N}-3$ \\
\hline & $(\mathrm{A}, \mathrm{B}, \mathrm{A}, \mathrm{B}, \mathrm{A}, \mathrm{B}, \mathrm{A}, \mathrm{B})$ & $(\mathrm{A}, \mathrm{B}, \mathrm{A}, \mathrm{B}, \mathrm{B}, \mathrm{A}, \mathrm{A}, \mathrm{A})$ & $(\mathrm{A}, \mathrm{B}, \mathrm{A}, \mathrm{B}, \mathrm{A}, \mathrm{A}, \mathrm{A}, \mathrm{A})$ \\
\hline & $(\mathrm{B}, \mathrm{A}, \mathrm{B}, \mathrm{A}, \mathrm{B}, \mathrm{A}, \mathrm{B}, \mathrm{A})$ & $(\mathrm{B}, \mathrm{A}, \mathrm{B}, \mathrm{A}, \mathrm{A}, \mathrm{B}, \mathrm{B}, \mathrm{B})$ & $(\mathrm{B}, \mathrm{A}, \mathrm{B}, \mathrm{A}, \mathrm{B}, \mathrm{B}, \mathrm{B}, \mathrm{B})$ \\
\hline & $(\mathrm{C}, \mathrm{D}, \mathrm{C}, \mathrm{D}, \mathrm{C}, \mathrm{D}, \mathrm{C}, \mathrm{D})$ & $(\mathrm{C}, \mathrm{D}, \mathrm{C}, \mathrm{D}, \mathrm{D}, \mathrm{C}, \mathrm{C}, \mathrm{C})$ & $(\mathrm{C}, \mathrm{D}, \mathrm{C}, \mathrm{D}, \mathrm{C}, \mathrm{C}, \mathrm{C}, \mathrm{C})$ \\
\hline & $(\mathrm{D}, \mathrm{C}, \mathrm{D}, \mathrm{C}, \mathrm{D}, \mathrm{C}, \mathrm{D}, \mathrm{C})$ & $(\mathrm{D}, \mathrm{C}, \mathrm{D}, \mathrm{C}, \mathrm{C}, \mathrm{D}, \mathrm{D}, \mathrm{D})$ & $(\mathrm{D}, \mathrm{C}, \mathrm{D}, \mathrm{C}, \mathrm{D}, \mathrm{D}, \mathrm{D}, \mathrm{D})$ \\
\hline & $(\mathrm{D}, \mathrm{D}, \mathrm{C}, \mathrm{D}, \mathrm{C}, \mathrm{D}, \mathrm{D}, \mathrm{C})$ & $(\mathrm{C}, \mathrm{D}, \mathrm{D}, \mathrm{C}, \mathrm{C}, \mathrm{D}, \mathrm{D}, \mathrm{D})$ & $(\mathrm{C}, \mathrm{D}, \mathrm{D}, \mathrm{C}, \mathrm{D}, \mathrm{D}, \mathrm{D}, \mathrm{D})$ \\
\hline & $(\mathrm{D}, \mathrm{C}, \mathrm{D}, \mathrm{C}, \mathrm{D}, \mathrm{D}, \mathrm{C}, \mathrm{D})$ & $(\mathrm{C}, \mathrm{D}, \mathrm{D}, \mathrm{D}, \mathrm{C}, \mathrm{D}, \mathrm{C}, \mathrm{C})$ & $(\mathrm{D}, \mathrm{C}, \mathrm{D}, \mathrm{D}, \mathrm{C}, \mathrm{C}, \mathrm{C}, \mathrm{C})$ \\
\hline & $(\mathrm{C}, \mathrm{D}, \mathrm{C}, \mathrm{D}, \mathrm{D}, \mathrm{C}, \mathrm{D}, \mathrm{D})$ & $(\mathrm{D}, \mathrm{C}, \mathrm{D}, \mathrm{D}, \mathrm{C}, \mathrm{D}, \mathrm{C}, \mathrm{C})$ & $(\mathrm{C}, \mathrm{D}, \mathrm{D}, \mathrm{C}, \mathrm{D}, \mathrm{D}, \mathrm{D}, \mathrm{D})$ \\
\hline & $(\mathrm{D}, \mathrm{C}, \mathrm{D}, \mathrm{D}, \mathrm{C}, \mathrm{D}, \mathrm{D}, \mathrm{C})$ & $(\mathrm{D}, \mathrm{C}, \mathrm{D}, \mathrm{D}, \mathrm{D}, \mathrm{C}, \mathrm{C}, \mathrm{C})$ & $(\mathrm{C}, \mathrm{D}, \mathrm{B}, \mathrm{C}, \mathrm{D}, \mathrm{D}, \mathrm{D}, \mathrm{D})$ \\
\hline & $(\mathrm{C}, \mathrm{D}, \mathrm{D}, \mathrm{C}, \mathrm{D}, \mathrm{D}, \mathrm{C}, \mathrm{D})$ & $(\mathrm{D}, \mathrm{C}, \mathrm{B}, \mathrm{A}, \mathrm{A}, \mathrm{B}, \mathrm{B}, \mathrm{B})$ & $(\mathrm{A}, \mathrm{B}, \mathrm{A}, \mathrm{C}, \mathrm{D}, \mathrm{D}, \mathrm{D}, \mathrm{D})$ \\
\hline & $(\mathrm{D}, \mathrm{D}, \mathrm{C}, \mathrm{D}, \mathrm{D}, \mathrm{C}, \mathrm{D}, \mathrm{C})$ & $(\mathrm{C}, \mathrm{D}, \mathrm{C}, \mathrm{B}, \mathrm{D}, \mathrm{C}, \mathrm{A}, \mathrm{A})$ & $(\mathrm{A}, \mathrm{B}, \mathrm{C}, \mathrm{A}, \mathrm{B}, \mathrm{B}, \mathrm{B}, \mathrm{B})$ \\
\hline & $(\mathrm{D}, \mathrm{C}, \mathrm{D}, \mathrm{D}, \mathrm{C}, \mathrm{D}, \mathrm{C}, \mathrm{D})$ & $(\mathrm{D}, \mathrm{C}, \mathrm{D}, \mathrm{D}, \mathrm{B}, \mathrm{C}, \mathrm{C}, \mathrm{C})$ & $(\mathrm{C}, \mathrm{D}, \mathrm{C}, \mathrm{B}, \mathrm{A}, \mathrm{A}, \mathrm{A}, \mathrm{A})$ \\
\hline & $(\mathrm{C}, \mathrm{D}, \mathrm{D}, \mathrm{C}, \mathrm{D}, \mathrm{C}, \mathrm{D}, \mathrm{D})$ & $(\mathrm{D}, \mathrm{C}, \mathrm{D}, \mathrm{D}, \mathrm{C}, \mathrm{B}, \mathrm{C}, \mathrm{C})$ & $(\mathrm{C}, \mathrm{D}, \mathrm{C}, \mathrm{A}, \mathrm{B}, \mathrm{B}, \mathrm{B}, \mathrm{B})$ \\
\hline
\end{tabular}

Table A-3: Nash equilibria. The format is $\left(a_{1, . .}, a_{8}\right)$ where $a_{i}, i=1, . .8$ is the action of player $i$. NE marked in bold have the property that all links are in NE.

\section{A.3 Graphs}

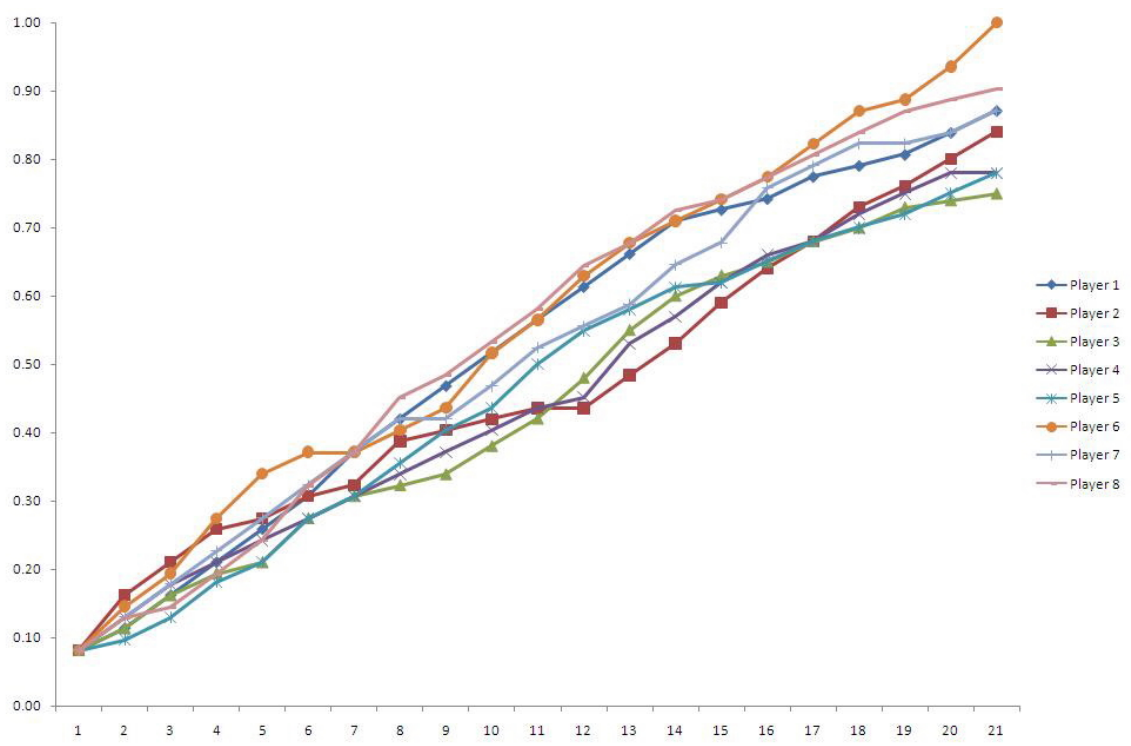

Figure A-1: Cumulative Distribution of Switches in N-1. 


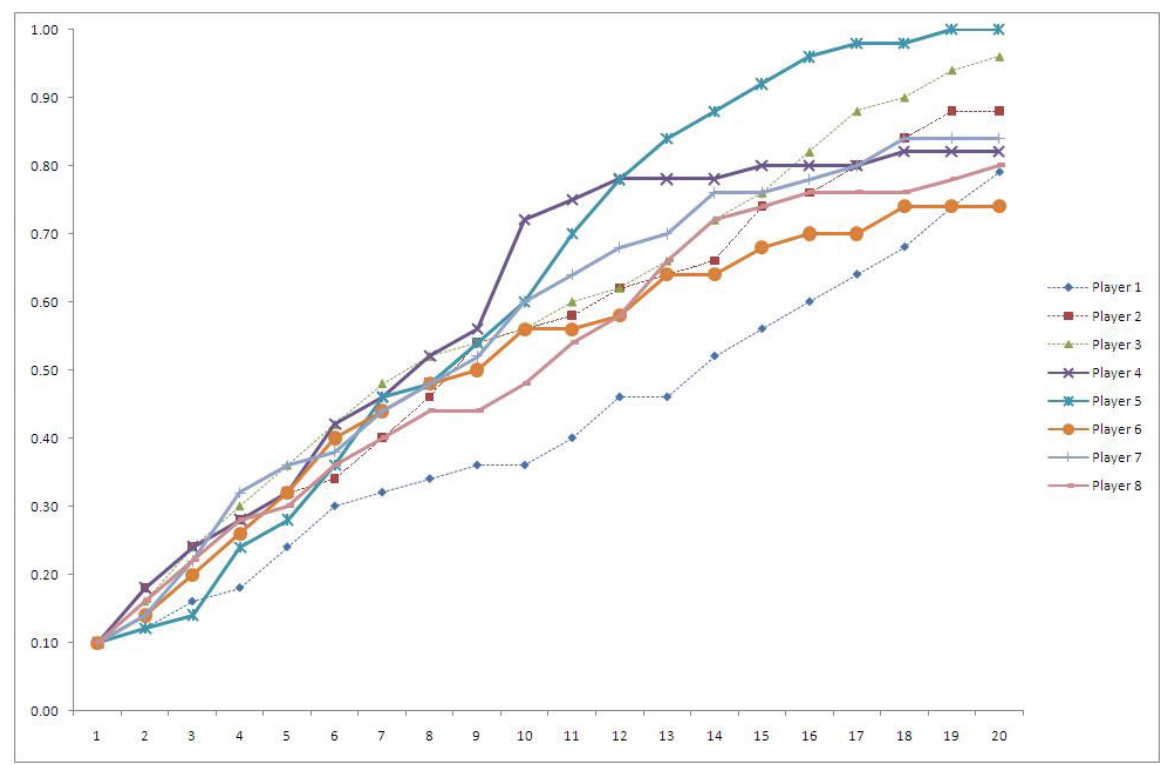

Figure A-2: Cumulative Distribution of Switches in N-3. The thinner/dashed lines correspond to players 1-3.

\section{A.4 Sample Instructions (Treatments N-1, N-2 and N-3)}

Welcome and thanks for participating at this experiment. Please read these instructions carefully. They are identical for all the participants with whom you will interact during this experiment.

If you have any questions please raise your hand. One of the experimenters will come to you and answer your questions. From now on communication with other participants is not allowed. If you do not conform to these rules we are sorry to have to exclude you from the experiment. Please do also switch off your mobile phone at this moment.

For your participation you will receive 2 Euros. During the experiment you can earn more. How much depends on your behavior and the behavior of the other participants. During the experiment we will use ECU (Experimental Currency Units) and at the end we will pay you in Euros according to the exchange rate 1 Euro $=75$ ECU. All your decisions will be treated confidentially.

\section{THE EXPERIMENT}

In the experiment you are linked up with some other participants in this room, which we will call your neighbours. You will play a game with your neighbours that we will describe below. Your neighbours in turn are of course linked up with you, but (possibly) also with other participants in the room. And their neighbours again are linked up with other participants and so on...

Note that your neighbours are not necessarily the participants who are located to your left and right in the physical layout of the computer laboratory.

During the experiment, you will be able to find out how many neighbours you have as well as their experimental identity, but not who they really are. This also means, of course, that your neighbours will not know your real identity.

The experiment lasts for 20 rounds. In each round you play a game with each of your neighbours. Your payoff in each round is the sum of payoffs obtained in all the games with your neighbours.

Each round consists of three stages, which we will describe in detail below. Here is a summary: 
1. In the first stage you choose an action in the game. Note that you have to choose the same action for all your neighbours.

2. In the second stage you can request information about your neighbours, your neighbours' neighbours etc... the actions they chose in the past period and the payoff they obtained in the past period, as well as about your own payoff.

3. In the third stage, the information you requested is displayed on the computer screen.

We will now describe the different stages in more detail.

\section{Stage 1 (Action Choice)}

In the first stage you have to choose one action in the game, which is described by the following table, which will be shown to you every time you choose an action.

\begin{tabular}{|l|l|l|l|l|}
\hline & $\mathrm{A}$ & $\mathrm{B}$ & $\mathrm{C}$ & $\mathrm{D}$ \\
\hline $\mathrm{A}$ & 20,20 & 40,70 & 10,60 & 20,30 \\
\hline $\mathrm{B}$ & 70,40 & 10,10 & 30,30 & 10,30 \\
\hline $\mathrm{C}$ & 60,10 & 30,30 & 10,10 & 30,40 \\
\hline $\mathrm{D}$ & 30,20 & 30,10 & 40,30 & 20,20 \\
\hline
\end{tabular}

In the table your actions and payoffs are given in dark grey and your neighbour's actions and payoffs in light grey. The table is read as follows (dark payoffs):

- If you choose A and your neighbour A, you receive 20

- If you choose A and your neighbour B, you receive 40

- $\quad$ If you choose $\mathrm{A}$ and your neighbour $\mathrm{C}$, you receive 10

- $\quad$ If you choose A and your neighbour D, you receive 20

- $\quad$ If you choose B and your neighbour A, you receive 70

- If you choose B and your neighbour B, you receive 10

- $\quad$ If you choose B and your neighbour C, you receive 30

- $\quad$ If you choose B and your neighbour D, you receive 10

- $\quad$ If you choose $\mathrm{C}$ and your neighbour $\mathrm{A}$, you receive 60

- $\quad$ If you choose $\mathrm{C}$ and your neighbour $\mathrm{B}$, you receive 30

- $\quad$ If you choose $\mathrm{C}$ and your neighbour $\mathrm{C}$, you receive 10

- $\quad$ If you choose $\mathrm{C}$ and your neighbour $\mathrm{D}$, you receive 30

- $\quad$ If you choose D and your neighbour A, you receive 30

- $\quad$ If you choose $\mathrm{D}$ and your neighbour $\mathrm{B}$, you receive 30

- $\quad$ If you choose D and your neighbour C, you receive 40

- $\quad$ If you choose D and your neighbour D, you receive 20

Note that your neighbour (light payoffs) is in the same situation as you are. This means that for your neighbour:

- $\quad$ If your neighbour chooses A and you A, your neighbour receives 20

- $\quad$ If your neighbour chooses A and you B, your neighbour receives 40

- If your neighbour chooses $\mathrm{A}$ and you $\mathrm{C}$, your neighbour receives 10

- $\quad$ If your neighbour chooses A and you D, your neighbour receives 20

- $\quad$ If your neighbour chooses B and you A, your neighbour receives 70

- $\quad$ If your neighbour chooses B and you B, your neighbour receives 10 
- $\quad$ If your neighbour chooses B and you C, your neighbour receives 30

- If your neighbour chooses B and you D, your neighbour receives 10

- If your neighbour chooses $\mathrm{C}$ and you $\mathrm{A}$, your neighbour receives 60

- If your neighbour chooses $\mathrm{C}$ and you $\mathrm{B}$, your neighbour receives 30

- $\quad$ If your neighbour chooses $\mathrm{C}$ and you $\mathrm{C}$, your neighbour receives 10

- If your neighbour chooses $\mathrm{C}$ and you $\mathrm{D}$, your neighbour receives 30

- If your neighbour chooses D and you A, your neighbour receives 30

- $\quad$ If your neighbour chooses D and you B, your neighbour receives 30

- If your neighbour chooses D and you C, your neighbour receives 40

- If your neighbour chooses D and you D, your neighbour receives 20

Remember that you have to choose the same action for all your neighbours. Your gross payoffs in each round are given by the sum of payoffs you have obtained in all games against your neighbours divided by the number of neighbours you have.

\section{Stage 2 (Information Request)}

In the second stage you can indicate which of the following pieces of information you would like to obtain

- $\quad$ the experimental identity of your neighbours

- $\quad$ the experimental identity of your neighbours' neighbours (2nd order neighbours)

- $\quad$ the experimental identity of your neighbours' neighbours' neighbours (3rd order)

- $\quad$ the experimental identity of your neighbours' neighbour's neighbours' neighbours (4th order neighbours)

Note that who is a neighbour of you does not change during the experiment. Hence once you have asked for this information in some round, it will be displayed in all future rounds. Note also that in order to receive information about your neighbours' neighbours' you first need to request information about your neighbours etc... The cost of requesting each of these pieces of information is 10. You only have to pay this cost once. In addition you can request information about the following items which (in principle) can change in every round.

- $\quad$ the actions chosen by your neighbours

- $\quad$ the actions chosen by your neighbours' neighbours

- $\quad$ the actions chosen by your neighbours' neighbours' neighbors

- $\quad$ the actions chosen by your neighbours' neighbour's neighbours' neighbours

- $\quad$ the payoffs obtained by your neighbours

- $\quad$ the payoffs obtained by your neighbours' neighbours

- $\quad$ the payoffs obtained by your neighbours' neighbours' neighbors

- $\quad$ the payoffs obtained by your neighbours' neighbour's neighbours' neighbours

- $\quad$ your own payoffs

Obviously, in order to receive information about your neighbours (or neighbours' neighbours') actions or payoffs you first need to request information about the experimental identity of your neighbours (neighbours' neighbours) etc...The cost of requesting each of these pieces of this information is 1 and you have to pay it each time you request this information anew. Your net payoffs in a round are your gross payoffs minus the cost of the information you requested.

\section{Stage 3 (Information Display)}

The information you have requested in Stage 2 is displayed on the screen for 40 seconds. 


\section{Control Questions}

Before we start the experiment please answer the following control questions on your screen.

1. Assume you have only one neighbour. She chooses action B and you action D. Which gross payoff will you get in this round?

2. Assume you have three neighbours and they choose action A, B and A. You choose action D. Which gross payoff will you get in this round?

3. True or False: My neighbours change in every round of the game.

4. True or False: My neighbours face the same payoff table as I do.

5. True or False: My neighbours are those sitting in the cubicles to my left and right. 